\title{
Músicas em movimento. Dos contextos, tempos e geografias da performance musical em Portugal
}

Music in movement. On contexts, times and geographies of musical performances in Portugal

Musiques en mouvement. Des contextes, des temps et des géographies de la performance musicale au Portugal

\section{Paula Abreu}

\section{OpenEdition}

\section{Journals}

Edição electrónica

URL: http://journals.openedition.org/rccs/1055

DOI: $10.4000 /$ rccs. 1055

ISSN: 2182-7435

\section{Editora}

Centro de Estudos Sociais da Universidade de Coimbra

\section{Edição impressa}

Data de publição: 1 dezembro 2004

Paginação: 159-181

ISSN: 0254-1106

\section{Refêrencia eletrónica}

Paula Abreu, « Músicas em movimento. Dos contextos, tempos e geografias da performance musical em Portugal », Revista Crítica de Ciências Sociais [Online], 70 | 2004, posto online no dia 01 outubro 2012, consultado o 10 dezembro 2020. URL : http://journals.openedition.org/rccs/1055 ; DOI : https:// doi.org/10.4000/rccs.1055 


\title{
Músicas em movimento. Dos contextos, tempos e geografias da performance musical em Portugal
}

\begin{abstract}
O texto propõe-se desenvolver uma reflexão acerca das dinâmicas territoriais dos mercados culturais, discutindo a forma como essas dinâmicas reflectem tensões inerentes à lógica própria da produção/criação cultural, às prioridades impostas pelo crescimento dos mercados da cultura (concorrência e disputa de públicos escassos) e a exigências de legitimação social e política das actividades culturais. A discussão far-se-á a partir da análise do caso particular do mercado do espectáculo musical no nosso país, recorrendo a dados produzidos no âmbito de um projecto de investigação realizado no CES/FEUC e recentemente finalizado. Os resultados produzidos possibilitam a identificação de traços marcantes relativos à geografia, aos tempos e aos contextos da produção de espectáculos musicais, permitindo a sua discussão no âmbito das principais linhas de estruturação das actuais políticas culturais (centrais e locais) e da esfera cultural no nosso país.
\end{abstract}

\section{Introdução}

Ao longo do último século, o universo da música tem sido particularmente marcado pela transformação dos seus processos de produção e pelo enorme crescimento da indústria fonográfica. Essas transformações mudaram radicalmente as condições de criação musical, tal como os modos da sua recepção e consumo. A introdução e popularização das técnicas e tecnologias de registo e reprodução sonora permitiram o alargamento sucessivo dos mercados da indústria da música, envolvendo expressões musicais distintas, consumidores diversos e espaços sucessivamente mais amplos. A globalização dos mercados da música, a concentração da sua produção e distribuição, os fenómenos de homogeneização e hegemonia dos repertórios produzidos e a estandardização dos consumos têm concentrado grande parte das discussões.

O domínio das polémicas em torno da indústria fonográfica e da música gravada tem deixado cair um espesso véu sobre as actividades do espectáculo musical ao vivo, tradicionalmente consideradas como referenciais na 
definição e institucionalização da esfera musical enquanto esfera artística. O carácter efémero dos concertos ou das apresentações performativas, os limites espaciais e sociais da sua difusão e as características técnicas e económicas dos seus modos de produção ditaram um crescente esbatimento da sua visibilidade perante o esmagador desenvolvimento da indústria da música gravada. ${ }^{1}$

Um tal esbatimento da projecção das actividades do espectáculo não supõe, contudo, o decréscimo da sua produção ou mesmo a perda de importância na criação e inovação musical, no apoio à actividade da indústria e na dinamização dos mercados urbanos da cultura. De facto, o âmbito da performance musical pública tem vindo a dilatar-se, assumindo um carácter intensamente diversificado, organizando-se em escalas variáveis e desenvolvendo-se em espaços e formatos cada vez mais heterogéneos. Uma diversificação que parece ter pulverizado o universo destas actividades.

Actualmente, a referência aos contextos espaciais de produção da performance musical é uma das vias que proporciona o resgate de algumas das questões que se colocam acerca desta esfera da actividade musical. Uma das abordagens que tem equacionado a relação entre espaço e performance musical é a que se interroga sobre os actuais cruzamentos entre políticas urbanas e políticas culturais locais e as suas implicações sobre a estruturação das esferas culturais e dos respectivos mercados. As questões suscitadas permitem equacionar a geografia urbana das actividades musicais performativas e interrogar o seu desenho a partir de uma lógica interpretativa que não se atém a critérios exclusivamente centrados sobre os universos musicais. Por outro lado, a abordagem que discute a configuração de cenas musicais - redes de criadores, produtores e consumidores que se articulam em torno de um género musical e se definem num determinado contexto e escala espacial (Bennett, 2004) - esboça um enfoque que sugere a pertinência de interrogações sobre as especificidades dos formatos organizacionais em jogo nos actuais contextos de produção da performance musical.

Tomando como ponto de partida estas linhas de interrogação, este texto propõe uma abordagem de algumas das tendências que marcam os actuais mercados do espectáculo musical ao vivo, usando para tal um conjunto de indicadores empíricos produzidos no contexto de um projecto de investi-

\footnotetext{
${ }^{1}$ De facto, trata-se de um fenómeno mais complexo do que a perda de visibilidade enunciada neste texto. A constituição de um universo musical não dependente da contínua actualização das performances musicais ao vivo e o desenvolvimento técnico e tecnológico das possibilidades de produção, registo e reprodução sonoros alteraram a estrutura dos campos musicais e a configuração das relações estabelecidas entre as diferentes formas das obras musicais (cf. Maisonneuve, 2002). Essa discussão excede em grande medida os objectivos do presente texto, pelo que aqui se optou por uma formulação mais simples e directamente associada ao objecto do trabalho.
} 
gação desenvolvido no Centro de Estudos Sociais da Faculdade de Economia da Universidade de Coimbra. ${ }^{2}$

Os objectivos são fundamentalmente dois: identificar alguns dos contornos mais vincados da distribuição geográfica, temporal e organizacional desta esfera de actividade cultural, quase desconhecida no nosso país; analisar a importância assumida pelo formato do festival na produção dos espectáculos de música, qualquer que seja a dimensão analítica considerada, e equacionar a sua relação com as lógicas inerentes aos processos de criação/ produção cultural e aos mercados da cultura, mas também com os mecanismos associados às exigências de legitimação social e política das actividades culturais. Com isto, pretende-se formular algumas interrogações pertinentes para uma abordagem crítica das políticas culturais e da sua relação com as lógicas e dinâmicas dos mercados culturais.

\section{O espectáculo musical em Portugal: indicadores e tendências}

O conhecimento empírico que temos acerca da esfera do espectáculo musical é actualmente muito limitado. As poucas análises disponíveis resultam de estudos indirectos, dominantemente centrados sobre a intervenção do Estado, central e local, no apoio e dinamização da actividade cultural. ${ }^{3}$ Os dados estatísticos disponíveis são escassos, dizendo respeito aos indicadores do espectáculo público e das despesas públicas no domínio da cultura, publicados pelo INE na série Estatísticas da Cultura, Desporto e Recreio e, de forma mais avulsa, nos Anuários Estatísticos das várias regiões. ${ }^{4}$

${ }^{2}$ Refiro-me ao projecto "Intermediários Culturais, Espaço Público e Cultura Urbana” (POCTI/ SOC/13151/1998), desenvolvido pelo Núcleo de Estudos sobre Cidades e Culturas Urbanas - NECCURB sob a coordenação de Carlos Fortuna e financiado pela Fundação para a Ciência e a Tecnologia, cujos resultados se encontram publicados em Fortuna et al., 2003.

3 Destacam-se os trabalhos desenvolvidos pelo Observatório das Actividades Culturais - OAC, que têm vindo a sistematizar dados e informação relativos às políticas culturais em Portugal (Santos, 1998), a apoios estatais a festivais de música (Martinho e Neves, 1999) e às despesas municipais com cultura (Neves, 2000).

${ }^{4}$ Os indicadores acerca dos espectáculos públicos centram-se sobre as suas diversas modalidades, recorrendo a nomenclaturas variáveis que têm vindo a ser alteradas ao longo do tempo, dificultando a sua análise comparada. Esses indicadores, entre os quais se encontram alguns referentes a espectáculos musicais, contabilizam fundamentalmente o número e o tipo de sessões realizadas, o número de espectadores e o número de recintos utilizados, sendo possível analisá-los de acordo com a sua distribuição temporal (a série temporal mais alargada situa-se entre 1961 e 2001, embora apenas para o conjunto global dos espectáculos públicos) e a sua distribuição geográfica. Só muito recentemente (desde 1999) foram introduzidas variáveis relativas a uma tipologia de recintos de espectáculo e das respectivas entidades proprietárias ou exploradoras. Os dados de que a Inspecção Geral das Actividades Culturais - IGAC (instituto que sucedeu à anterior Direcção Geral dos Espectáculos) dispõe, e que resultam dos licenciamentos de recintos, entidades promotoras de espectáculos e dos próprios espectáculos, provavelmente permitiriam melhorar este conhecimento. Contudo, até ao momento, esta informação não se encontra tratada e disponível para consulta pública. 
É conhecido o carácter a vários títulos rudimentar dos indicadores aí contidos. Todavia, na sua reconhecida fragilidade, os dados das Estatísticas da Cultura permitem evidenciar um aspecto que não deixa de ser importante: aquele que diz respeito ao alargamento das actividades performativas, quer na vertente da sua produção e oferta, quer na vertente da participação e da procura por parte dos seus públicos.

Esta tendência de dinâmica crescente do espectáculo ao vivo espelha as mudanças socioculturais ocorridas no nosso país nas últimas décadas, que, como temos vindo a referir no contexto de outros trabalhos (Fortuna, Ferreira e Abreu, 1999; Fortuna e Silva, 2001; Fortuna, 2002), têm projectado a cultura para o centro das arenas política, social e mesmo económica.

Manifestando-se de forma diferenciada em diversos sectores da actividade cultural, a nova centralidade da cultura traduz a convergência de factores internos, nacionais e locais, e de factores externos, associados à intensificação dos processos de globalização.

No plano interno, destacam-se algumas das transformações de carácter sócio-espacial, respeitantes aos processos de qualificação escolar e profissional das populações, sobretudo das gerações mais jovens, e à sua crescente concentração em mais e maiores centros urbanos. Mas devem igualmente considerar-se as transformações económicas, sobretudo as que concernem o desenvolvimento e a expansão das indústrias culturais, do lazer e da informação. Estes dois tipos de factores foram constituindo um crescente interesse e apetência pelo consumo de objectos e serviços culturais, cada vez mais próximos, abundantes e diversificados. ${ }^{5}$ As cidades tornaram-se os espaços privilegiados dos mercados culturais, oferecendo oportunidades crescentes quer no domínio da criação, produção e distribuição cultural, quer no domínio dos consumos e das práticas de cultura. ${ }^{6}$

Simultaneamente, do ponto de vista externo, a globalização dos mercados da cultura, quer nos segmentos mais especializados da criação e produção artística, quer nas diversas fileiras das indústrias culturais, contribuiu para acentuar as necessidades de concentração urbana das actividades culturais. A intensificação dos fluxos de circulação de bens ou obras culturais e a constituição de circuitos culturais cada vez mais organizados a escalas nacionais e internacionais ampliou a geografia dos campos culturais

\footnotetext{
${ }^{5}$ Sobre as transformações do consumo e da prática cultural no nosso país ver Conde (1997) e Fortuna, Ferreira e Abreu (1999).

${ }^{6}$ Pedro Costa trabalha com particular atenção estes cruzamentos entre as economias urbanas e economias da cultura, analisando os "efeitos de meio" que explicam a associação entre a esfera da cultura e os espaços das cidades (Costa, 1999, 2000 e 2002). Também Augusto Santos Silva desenvolve um conjunto interessante de argumentos acerca das relações entre os "ambientes urbanos" e a constituição das esferas culturais à escala local (Silva et al., 1998, e Silva, 2002).
} 
(Lash e Urry, 1994), arrastando os seus operadores e as cidades onde estes baseiam a sua actividade para uma competição que deixa de ter por referência o espaço regional ou nacional.

Pierre-Michel Menger (1993) chama a atenção para as dinâmicas contraditórias geradas por este conjunto de processos. Na sua opinião, eles tendem a estimular a competição cultural entre cidades, favorecendo estratégias de descentralização da actividade cultural. Mas, simultaneamente, sobretudo no que diz respeito a segmentos da criação artística mais especializados, estes processos tendem a estimular a centralização destas actividades nos grandes centros urbanos, onde se potenciam os efeitos de massa crítica e economias de escala, favorecendo a hegemonia das grandes capitais culturais.

É, aliás, por referência a este conjunto de dinâmicas culturais e económicas que podemos perceber a forma como, em Portugal, têm vindo a estruturar-se as políticas públicas no domínio da cultura. Estas têm vindo a caracterizar-se por uma relativa autonomização das esferas de intervenção do Estado central e do Estado local, que deixam ao Estado central o principal papel de apoio às instituições, criadores e equipamentos culturais com capacidade de projecção nacional e internacional e atribuem cada vez mais ao Estado local as competências de dinamização dos ambientes culturais locais. ${ }^{7}$

Numa primeira abordagem, esta divisão de responsabilidades políticas parece dar conta de um esforço meritório de investimento e descentralização cultural. No entanto, o retrato dos ambientes culturais das cidades médias portuguesas, que tem vindo a ser revelado por estudos relativamente pontuais, desvela paisagens urbanas que, para além das duas maiores cidades do país, são caracterizadas pela frágil infra-estruturação de equipamentos e serviços culturais, mesmo quando considerados os segmentos mais especializados e localizados dos mercados das indústrias culturais (cinema, livro, música gravada...). Mostra igualmente uma oferta cultural urbana pouco densa e relativamente volúvel, ancorada sobretudo em operadores de intermediação cultural (programação, divulgação e distribuição cultural), mais do que em agentes de produção e criação localizados nessas cidades.

Éà luz deste quadro mais geral, cujos traços elementares acabei de enunciar, que entendo poder ser feita a discussão acerca do crescimento da esfera do espectáculo no nosso país. As suas principais características estruturais,

\footnotetext{
${ }^{7}$ Claudino Ferreira dá conta dessa dualidade da intervenção do Estado quando analisa o lugar que os grandes eventos culturais têm vindo a ocupar como instrumentos de política cultural no nosso país (Ferreira, 1998).
} 
embora se relacionem com especificidades do tecido cultural e urbano português, actualizam, seguramente, os constrangimentos e as possibilidades associadas às actuais dinâmicas globais da economia e da cultura. Torna-se, por isso, necessária uma perspectiva de observação que centre o seu olhar sobre as formas locais da(s) cena(s) musical(ais). Para além de indicadores que apontam o crescimento da oferta de espectáculos ao vivo no nosso país, é fundamental procurar o conhecimento das suas configurações específicas, quer no que diz respeito a segmentos culturais particulares (neste caso, o segmento do espectáculo musical), quer ainda nas suas dimensões espaciais e geográficas.

De facto, ao contrário do que acontece nos domínios do que Diana Crane (1992) designou como recorded cultures (de que é um exemplo típico o universo da música gravada), cuja produção, distribuição e consumo são cada vez mais desmaterializados e deslocalizados, as esferas das actividades culturais performativas dependem sempre de uma (re)produção localizada. E, embora os circuitos de apresentação e performance estejam já hoje organizados a escalas nacionais ou internacionais, eles dependem sempre de tempos, espaços, operadores e consumidores locais ou localizados em lugares concretos. As lógicas culturais e económicas contemporâneas ditam, como observámos anteriormente, as cidades como centros privilegiados do espectáculo musical.

Foi neste sentido que, no âmbito do projecto de investigação já referido, se procurou desenvolver um instrumento empírico e analítico que nos permitisse captar com mais detalhe a cartografia do espectáculo de música ao vivo e a sua articulação com os contextos sociais, económicos e políticos das diferentes regiões e cidades do país.

Esse instrumento foi desenvolvido em formato de Observatório de Imprensa e concebido com o objectivo de recorrer à informação contida na imprensa como suporte empírico para a elaboração de agendas anuais de espectáculos musicais. ${ }^{8}$ Elaboradas para os anos de 2000 e 2001, essas agendas resultam da aplicação de um modelo de análise de conteúdo que procurou sintetizar informações básicas acerca dos espectáculos, construindo um instrumento analítico capaz de cartografar dimensões essenciais do mercado do espectáculo musical ao vivo: as temporalidades desse mercado;

\footnotetext{
${ }^{8}$ O Observatório de Imprensa foi elaborado com base em dois jornais nacionais - Jornal de Notícias e Público -, seleccionados de acordo com critérios relativos à sua estrutura editorial e à sua cobertura nacional. Constituído por todas as notícias publicadas nesses diários ao longo de $2000 \mathrm{e}$ 2001 e referentes a espectáculos musicais realizados ou a realizar em Portugal nos mesmos anos, o corpus de documentos deste Observatório incluiu 10678 registos. Para uma descrição detalhada da estrutura do Observatório de Imprensa e do respectivo instrumento de classificação e análise de informação, ver Fortuna et al., 2003, capítulo 1.
} 
a sua distribuição na geografia do país; os contextos ou modos da sua produção; os operadores culturais envolvidos na sua organização; os espaços ou equipamentos onde acontecem os espectáculos. ${ }^{9}$

\section{Contextos de realização e circuitos da música ao vivo}

Um dos objectivos da análise dos dados classificados a partir do Observatório de Imprensa centrou-se sobre a possibilidade de identificar alguns dos contextos da organização de eventos musicais, de modo a distinguir os contributos dados à esfera musical por formatos de produção diversos, associados a realizações especificamente musicais ou a outro tipo de iniciativas de dinamização e animação cultural local.

Estava em causa a operacionalização de hipóteses que pareciam adequadas à análise e descrição da situação do espectáculo musical no nosso país. A primeira dessas hipóteses actualiza um pressuposto de acordo com o qual as cidades e os contextos geográficos (nomeadamente nacionais) com esferas de actividade cultural e artística particularmente densas, diversificadas e sedimentadas revelariam modelos de oferta cultural e, portanto, de espectáculo musical vinculados à dinâmica regular de uma significativa rede de agentes. A segunda hipótese enunciava o princípio segundo o qual as cidades e os contextos geográficos caracterizados por uma esfera cultural fragilmente consolidada e por uma volátil oferta cultural tenderiam a desenvolver estratégias de produção e inserção no universo do espectáculo musical baseadas na produção de eventos culturais diversos, caracterizados por uma duração limitada no tempo e por reedições de regularidade muito variável.

No nosso país, as fragilidades estruturais do tecido e da dinâmica das actividades culturais, mais evidentes nos meios urbanos de pequena e mesmo de média dimensão, têm frequentemente vindo a ser contornadas pela instalação de lógicas de produção, difusão e, sobretudo, programação assentes

\footnotetext{
9 Tratando-se do recurso a uma estratégia de produção secundária de dados, a formulação destas agendas anuais de espectáculos noticiados assumiu um pressuposto geral acerca da validade da informação nelas contida. Um pressuposto sobre a existência de uma forte correlação entre as notícias que surgem na imprensa (nomeadamente nos dois jornais usados por nós como fontes documentais) e os espectáculos efectivamente anunciados e/ou realizados. De facto, a imprensa constitui um dos sistemas de intermediação entre a esfera da produção e distribuição cultural e a esfera da prática e do consumo cultural, actuando como um sistema de gatekeeping (Hirsh, 1972; Crane, 1992), isto é, de selecção e tradução da informação entre os dois campos da actividade cultural. Neste sentido, embora a informação contida na imprensa não espelhe directamente a realidade, ela contém uma representação que não se pode distanciar em absoluto dessa realidade. O pressuposto de correlação entre espectáculos noticiados e espectáculos realizados assenta exactamente nesse estatuto de intermediação que caracteriza o sistema de informação da imprensa. Os indicadores elaborados a partir dos dados classificados são, portanto, entendidos como indicadores brutos da realidade, com potencialidades interessantes de ilustração sobre a variabilidade de diferentes dimensões da realidade.
} 
na realização de eventos culturais de diversa natureza. ${ }^{10}$ Caracterizados por uma maior ou mais intensa oferta cultural, concentrada em espaços e tempos restritos, esses eventos assumem duas expressões fundamentais: a organização de festas (urbanas, populares ou mesmo académicas) multifacetadas; e a produção de eventos culturais mais ou menos especializados, de duração limitada, em espaços circunscritos e de ocorrência regular, frequentemente designados como festivais.

A importância das festas está associada a um alargamento das formas de cultura de representação, ${ }^{11}$ que desde sempre atravessaram os rituais de celebração (religiosos, académicos, civis ou políticos). Hoje, encontram-se disseminadas no país, muito para além da tradicional esfera religiosa e do espaço rural, acompanhando a descentralização das instituições do Estado local e do próprio sistema de ensino superior. As funções de representação das festas - religiosas, populares, das cidades ou académicas - cruzam-se com outras lógicas que atravessam as relações entre a cultura e a política. Associam-se a estratégias de promoção das imagens das cidades e ao seu marketing turístico e cultural, a políticas de integração social e identitária, ou ainda a oportunidades de dinamização e programação cultural (Fortuna, 2002).

O recurso ao modelo de organização de festivais parece revelar uma convergência de alguns destes factores com condicionantes específicas da esfera cultural. A flexibilidade do modelo organizacional destes eventos permite minorar as dificuldades que muitos operadores culturais (públicos e privados) têm em sustentar uma produção e uma programação regulares. Simultaneamente, facilitam a congregação de vontades de criadores e produtores para o investimento em projectos que reúnam diferentes parceiros, suscitem a partilha de experiências, ofereçam oportunidades de projecção nacional ou mesmo internacional do seu trabalho e de integração em redes ou circuitos culturais internacionais. Os festivais constituem ainda um modelo de organização cultural que serve os esforços daqueles que se dedicam a expressões artísticas marginais ou ensaiam vias de afirmação na esfera cultural e a programação em áreas especializadas, com procuras limitadas ou de elasticidade reduzida. Possibilitam também uma aproximação à política de autarquias locais ou a opções estratégicas de mecenato de empresas, potenciando oportunidades de promoção de imagens de prestígio de instituições, de grupos e profissionais, bem como dos locais que os acolhem (cidades, concelhos, paisagens...) ou instituições que os apoiam ou patrocinam.

\footnotetext{
${ }^{10}$ Sobre a estrutura da oferta cultural em cidades portuguesas de pequena e média dimensão, ver Silva et al., 1998, e Silva, 2002.

${ }^{11}$ Sobre a noção de cultura de representação, ver Silva, 1994.
} 
Com base na informação sintetizada nas agendas culturais elaboradas para os anos de 2000 e 2001, foram construídos indicadores sobre os contextos de organização dos espectáculos musicais noticiados, que permitiram operacionalizar a análise de algumas das tendências que acabei de apresentar.

Foram consideradas três categorias de classificação dos contextos de produção dos espectáculos musicais: espectáculos agenda, festas e festivais. A primeira categoria alberga as actividades de equipamentos, instituições ou agentes culturais, cuja programação se desenvolve de forma mais ou menos regular; A categoria festas classifica os programas de festas que assinalam celebrações religiosas ou cívicas, populares ou académicas, que têm lugar sobretudo entre os meses de Maio e Setembro. As festas pressupõem uma combinação híbrida de actividades rituais, lúdicas, de entretenimento e de programação cultural, da qual faz parte uma habitual e forte componente de espectáculo musical. Por último, a categoria festivais enquadra as agendas de eventos culturais que concentram num tempo curto e num espaço normalmente delimitado uma intensa programação musical (ou multidisciplinar). Frequentemente designados como festivais, jornadas, projectos, ciclos..., esses eventos têm, na maioria, um carácter disciplinar ou temático.

De acordo com as hipóteses atrás enunciadas, seria de esperar que os espectáculos agenda constituíssem a categoria mais representativa da oferta de música ao vivo em contextos culturais fortemente sedimentados. No mesmo sentido, o perfil da estrutura da oferta cultural no nosso país e, em particular, nas cidades portuguesas apontaria para uma importância significativa de organizações extraordinárias, como as festas e festivais, na dinamização do universo de apresentações musicais ao vivo, particularmente fora dos dois grandes pólos de actividade cultural no país (Lisboa e Porto).

Os dados mostram, para os dois anos em causa (2000 e 2001), agendas de espectáculos musicais noticiados claramente marcadas por três grandes tendências.

A primeira e mais genérica dessas tendências diz respeito ao perfil dicotómico da imagem da esfera musical portuguesa projectada pelos media (gráfico 1).

GRÁFICO 1 - Distribuição dos registos de Espectáculos pelos principais sub-temas (\%)

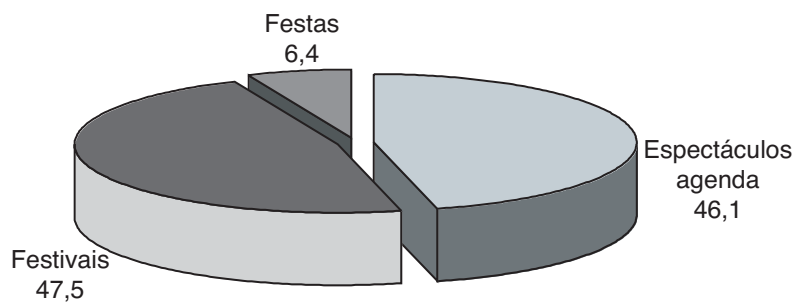


A realidade que esta imagem reflecte resulta essencialmente de dois contributos distintos. Por um lado, a actividade dos agentes no campo musical, assim como de numerosos outros operadores mais ou menos marginais a esse mesmo campo na produção de actividades de apresentação musical ao vivo. Por outro lado, a (variável) institucionalização de eventos musicais diversos, não necessariamente associados a agentes de produção, criação ou difusão musicais.

O que mais se destaca, no entanto, é o evidente equilíbrio entre os espectáculos identificados com um enquadramento específico em festivais e aqueles que decorrem da actividade mais ou menos regular dos agentes da produção e divulgação musical no nosso país (os espectáculos agenda). E se é verdade que devemos temperar a interpretação destes resultados com as precauções que a natureza dos dados impõe, também é verdade que não podemos ignorar os indícios que os mesmos nos dão relativamente a uma tendência que vem sendo enunciada a partir de outros indicadores. ${ }^{12}$

Parece, portanto, claro que o recurso ao formato organizacional e cultural dos festivais constitui um traço marcante da estruturação do universo da música ao vivo, complementando as formas mais tradicionais de organização do espectáculo musical.

O contributo dado pela multiplicação do tipo e número de festas é substancialmente mais diminuto, traduzindo circunstâncias diversas. As festas são acontecimentos multifacetados, que envolvem programações lúdico-culturais muito diversas. Embora a sua realização envolva uma constante componente musical, a sua projecção, nomeadamente mediática, não se fará necessariamente por via dos espectáculos musicais que incluem. Essa característica, de eventos multifacetados, contrasta, aliás, com o contributo dado pelos festivais, que oferecem, na sua maioria, uma programação disciplinar, frequentemente especializada (em géneros ou formas musicais específicas), e uma organização com mais preocupações de promoção externa. ${ }^{13}$

Esta dicotomização será sintomática da fragilidade da esfera musical portuguesa, particularmente dependente de circuitos de distribuição não directamente associados a infra-estruturas culturais locais. Uma hipótese

\footnotetext{
${ }_{12}$ Para além dos resultados empíricos de estudos citados anteriormente, o trabalho de José Soares Neves e Teresa Duarte Martinho (1999) sobre a evolução dos apoios concedidos pelo Estado Central à organização de festivais esboça uma significativa tendência de crescimento e proliferação destes acontecimentos e do suporte público que lhes tem sido dado.

${ }_{13}$ A popularização deste formato organizativo criou uma espécie de mercado de festivais, dinamizado por uma dupla lógica competitiva: i) a que está subjacente à captação de apoios públicos, sobretudo dos organismos centrais do Ministério da Cultura, ou mesmo privados; ii) a que se relaciona com a disputa de reconhecimento (por parte dos media e por parte de potenciais públicos). Essa competição "mercantil" reflecte-se em fortes investimentos promocionais que têm uma tradução óbvia na imprensa.
} 
que é corroborada pela análise mais detalhada dos dados do Observatório de Imprensa, nomeadamente pela observação da distribuição sazonal e geográfica dos espectáculos classificados em cada uma das categorias de análise.

A segunda grande tendência traduzida pelas agendas de espectáculos noticiados indicia uma clara diferenciação dos ritmos e temporalidades associadas a cada um dos três contextos de produção de espectáculos (gráficos 2 e 3).

\section{GRÁFICO 2 - Distribuição mensal de Espectáculos realizados no contexto de Festas, Festivais e Espectáculos agenda em 2000}

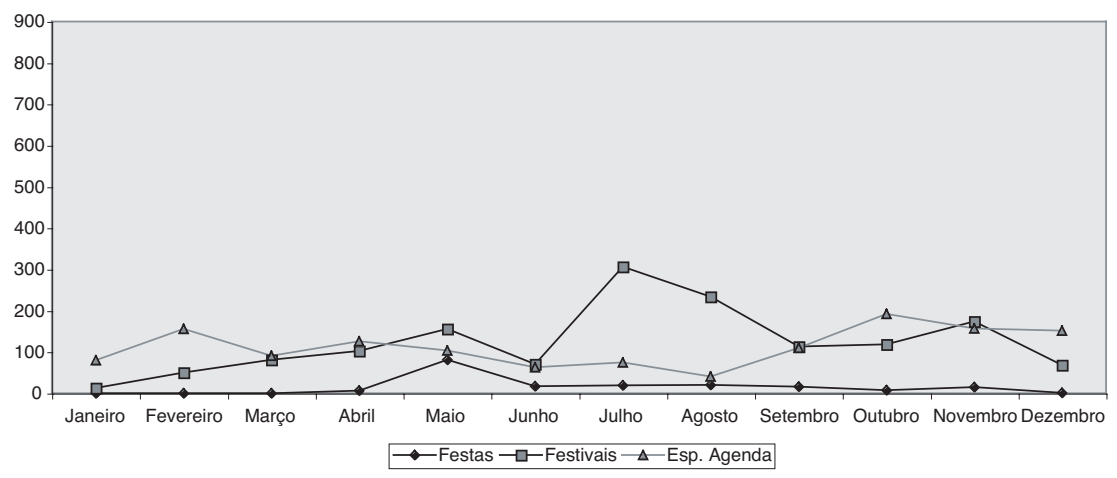

GRÁFICO 3 - Distribuição mensal de Espectáculos realizados no contexto de Festas, Festivais e Espectáculos agenda em 2001

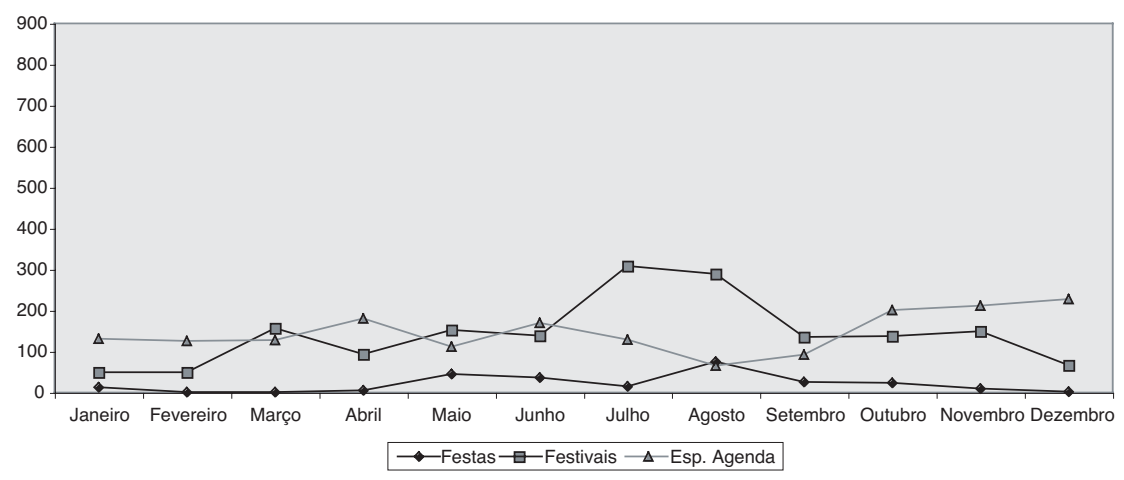

Os espectáculos agenda, que decorrem da actividade regular de instituições, serviços, equipamentos ou criadores, acontecem com regularidade ao longo de todo o ano, numa sequência que tem ritmos mais intensos nos meses que vão do início do Outono ao final da Primavera e ritmos mais brandos nos meses de Verão. A sua produção reflecte lógicas eminentemente artísticas e associa-se aos ritmos dominantes das actividades sociais, políticas ou económicas, que têm anualmente períodos de maior acalmia. 
Como seria de esperar, e não obstante as variações anuais associadas aos calendários específicos das temporadas musicais, os espectáculos agenda apresentam uma maior constância ao longo do ano, distinguindo-se dos ciclos temporais de festivais e festas.

Os festivais são eventos com uma temporalidade inversa à que observámos para as agendas regulares, iniciando uma actividade mais intensa com a Primavera e estendendo-se até aos meses de Outono. A sua organização parece resultar de estratégias de superação de deficiências na produção e circulação de obras performativas em campos musicais especializados e em contextos geográficos específicos. O pico da ocorrência dos festivais acontece no Verão, nos meses de Julho e Agosto, revelando a forma como estes eventos musicais, embora orientados por objectivos artísticos, têm vindo a ser associados a estratégias políticas locais, que procuram promover actividades lúdico-culturais capazes de atrair e fixar turistas e de projectar no exterior (no âmbito regional, nacional ou mesmo internacional) a imagem das cidades ou dos concelhos.

As festas, por seu turno, assinalam calendários completamente distintos, sendo mais frequentes no Verão e, no caso das festas académicas, nos meses de Abril ou Maio, antecedendo o final do ano lectivo. ${ }^{14}$ São acontecimentos associados a celebrações públicas (rituais cívicos, políticos e religiosos), promovidos ou apropriados pelas autoridades locais, que os tomam como pretexto e oportunidade para a realização de actividades de animação cultural dirigidas às populações locais, mas também aos visitantes, mais frequentes na época estival. As festas constituem, aliás, um dos principais, senão mesmo o principal instrumento de programação cultural ao alcance de muitas autarquias locais. E em contextos urbanos de frágil ou débil estruturação cultural, as festas locais representam os momentos altos das temporadas locais.

A comparação das distribuições anuais de espectáculos agenda, festivais e festas em 2000 e em 2001 permite dar conta da complementaridade dos contextos ou modos de produção do espectáculo. Mas permite também destacar como, apesar das variações específicas associadas a cada modo de produção, o número de espectáculos realizados no âmbito de festivais se encontra relativamente próximo daqueles que acontecem no âmbito da actividade regular da esfera musical. Trata-se de um indicador que mais uma vez indicia a importância destes eventos na dinamização da oferta de espectáculos no nosso país.

\footnotetext{
${ }^{14}$ Em alguns casos, as festas académicas têm um segundo momento marcante: o que se segue ao início do ano lectivo, quando têm lugar os principais rituais e actividades de recepção e acolhimentos de estudantes recém-chegados ao Ensino Superior (e que se situa entre os meses de Outubro e de Novembro).
} 
A terceira e última tendência decorre da análise dos padrões de distribuição geográfica de espectáculos agenda e de festivais e permite relacionar esses mesmos padrões com os mais vincados vectores de estruturação da oferta cultural no país (polarização nas áreas urbanas de Lisboa e Porto e assimetrias entre litoral e interior - gráficos 4 e 5).

GRÁFICO 4 - Distribuição geográfica dos registos de Festas, Festivais e Espectáculos pontuais por NUTS II e III, no ano de 2000

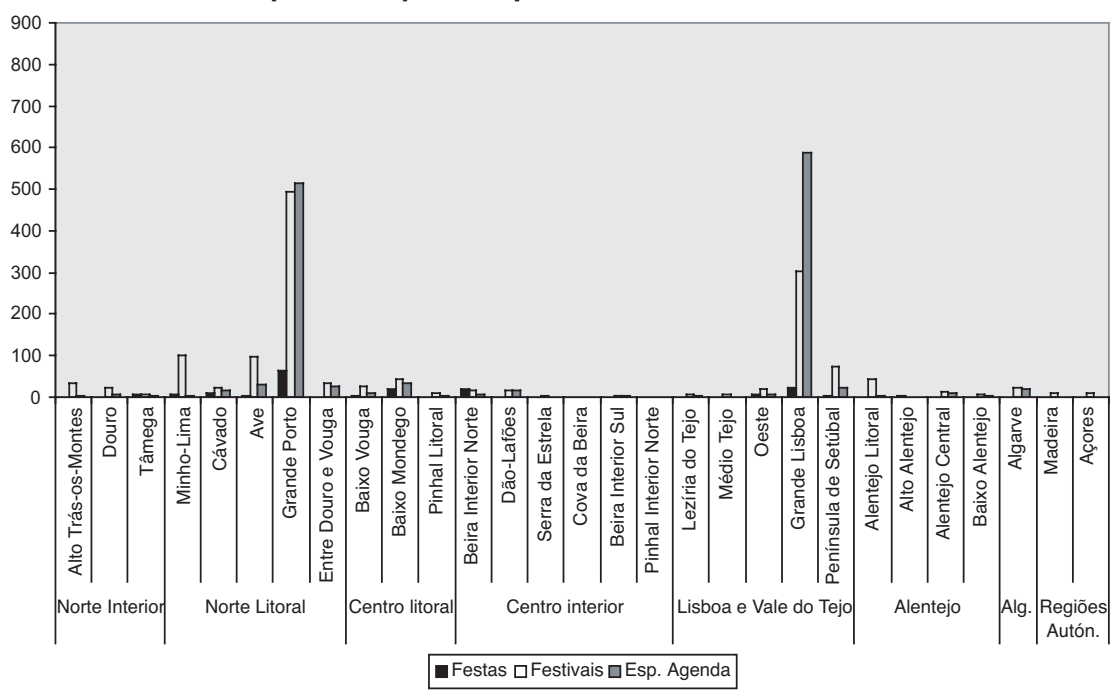

GRÁFICO 5 - Distribuição geográfica dos registos de Festas, Festivais e Espectáculos agenda por NUTS II e III, no ano de 2001

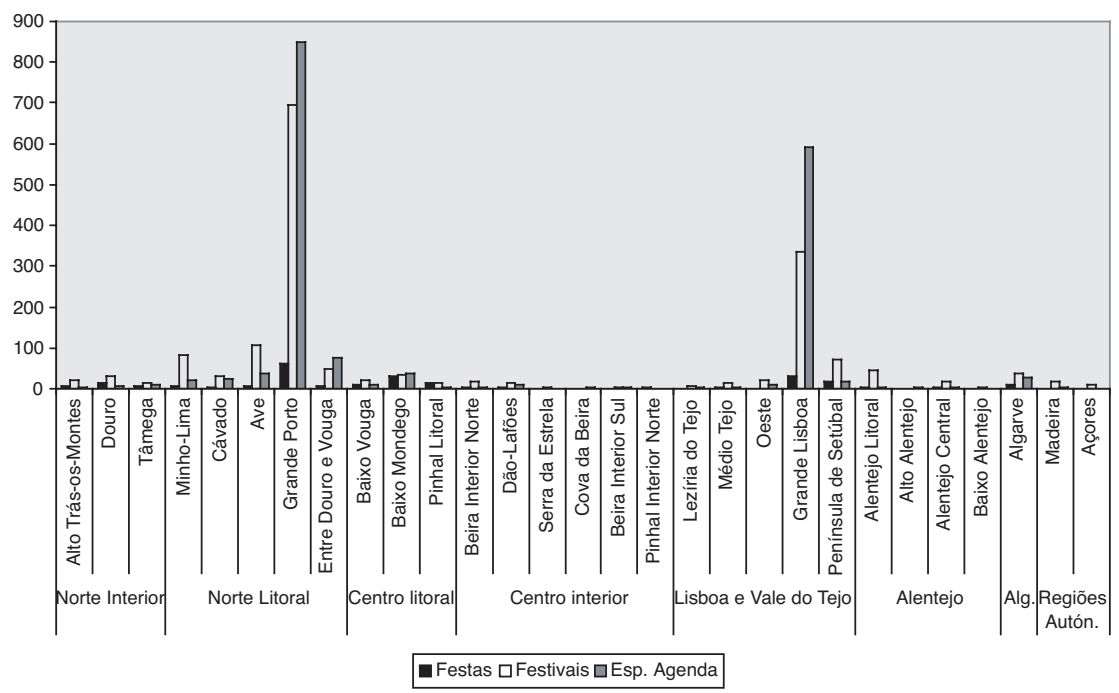


As distribuições geográficas dos espectáculos dão conta de um padrão relativamente estável nos dois anos considerados neste trabalho. Uma observação cuidada dessas distribuições permite destacar três aspectos principais. O primeiro diz respeito à já observada concentração de espectáculos musicais em Lisboa e Porto, sejam estes realizados no âmbito de festas e festivais ou resultado da dinâmica artística das esferas musicais destas cidades. O segundo remete para a comparação dos perfis de distribuição de espectáculos agenda e de festivais nas áreas do Grande Porto e da Grande Lisboa. Embora estes constituam os dois grandes pólos culturais do país, os dados indiciam uma estrutura diferencial da oferta musical nos dois centros urbanos. Lisboa evidencia uma oferta regular mais intensa, enquanto o Porto mostra uma maior dependência relativamente à realização de festivais. E o terceiro dá conta do que acontece fora dos grandes centros urbanos, onde o número de espectáculos noticiados é substancialmente mais reduzido, sendo o contributo dos festivais frequentemente mais importante do que o da oferta local mais ou menos regular (espectáculos agenda).

O facto mais relevante da estrutura geográfica da oferta de espectáculos de música ilustrada nos gráficos 4 e 5 é, seguramente, aquele que dá conta da incontornável hegemonia dos dois maiores centros urbanos do país, observável para os três circuitos de produção aqui representados.

E, como referimos anteriormente, embora possamos admitir que a natureza das fontes e dos dados contribua para ampliar o efeito de concentração de espectáculos musicais registados em Lisboa e no Porto, não é difícil admitir a verosimilhança desta situação. Aliás, a análise comparada das características da oferta musical nestas duas cidades contribui para reforçar essa ideia, mostrando diferenças que têm um significado importante, pela complexificação que introduzem na tese da macrocefalia das duas áreas urbanas.

No gráfico 6 podemos observar melhor a forma como a imprensa representa as esferas do espectáculo musical do Grande Porto e da Grande Lisboa, relacionando-as com modos de produção devedores de lógicas desigualmente distribuídas.

Relativamente a Lisboa, a imprensa faz-se eco de uma arena do espectáculo musical menos dependente do modelo organizativo dos festivais e mais abundante em espectáculos agenda, quer eles resultem de agendas culturais regulares (de instituições e equipamentos culturais), quer sejam o produto de uma intensa dinâmica dos mercados culturais e, em particular, do mercado da música. É em Lisboa que estão sediadas algumas das maiores instituições de produção e de ensino musical (entre outras, a Orquestra Gulbenkian, Teatro Nacional de S. Carlos, Orquestra Sinfónica Portuguesa, 
GRÁFICO 6 - Distribuição geográfica dos registos de Festas, Festivais e Espectáculos agenda nas áreas da Grande Lisboa e do Grande Porto

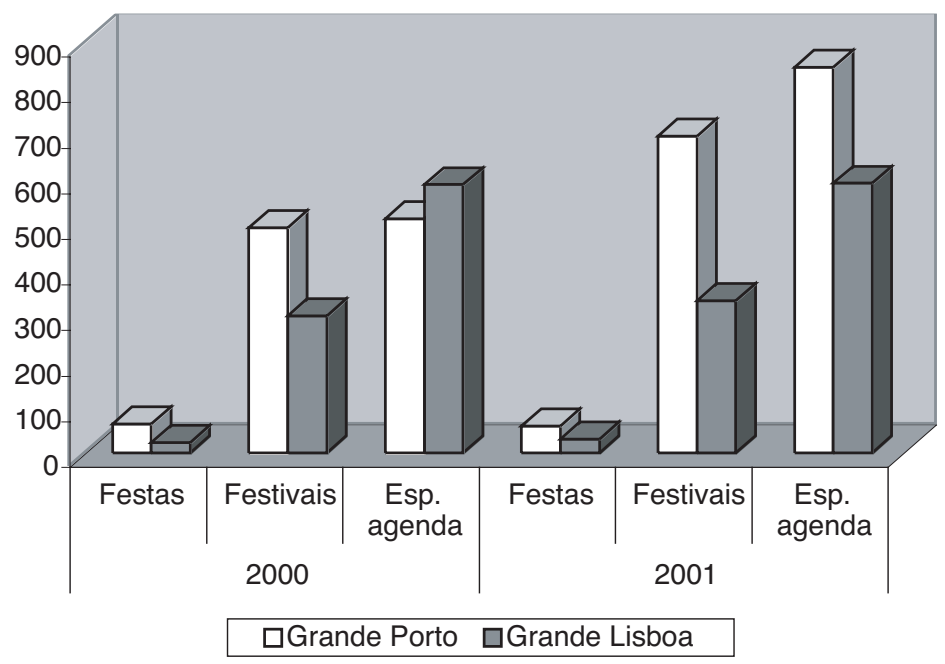

Orquestra Metropolitana de Lisboa, Hot Club de Portugal, Escola Superior de Música, Conservatório Nacional...), os maiores e mais dinâmicos equipamentos culturais (de que são exemplo o Centro Cultural de Belém, a Fundação Calouste Gulbenkian, o Teatro Nacional de S. Carlos, o Coliseu dos Recreios, o Teatro Camões, o Pavilhão Atlântico,...) e se concentram múltiplas actividades de produção e intermediação cultural (produtoras de espectáculos, produtoras musicais, editoras, televisões, rádios nacionais...).

O Porto projecta a imagem de uma arena musical performativa onde os festivais parecem ocupar um lugar tão importante quanto o da produção associada à iniciativa de agentes locais. Dispondo de importantes equipamentos culturais (como o Teatro Rivoli, o Coliseu, o Auditório do Museu de Serralves, o Teatro Nacional de S. João, o Auditório Carlos Alberto, o Palácio de Cristal/Pavilhão Rosa Mota...), a cidade acolhe um menor número de instituições musicais relevantes (a recente Escola Superior de Música e de Artes do Espectáculo, o Conservatório Nacional, a recém-reestruturada Orquestra Nacional do Porto, o Círculo Portuense de Ópera...) e, sobretudo, um mercado de produção e intermediação menos denso e activo.

O projecto da Porto 2001 - Capital Europeia da Cultura foi, neste contexto, particularmente relevante. Envolvendo várias dimensões de intervenção na cidade, incorporou em duas das mais relevantes - a programação cultural e os equipamentos culturais - uma forte preocupação com o campo musical. Estimulou a consolidação do projecto da Orquestra Nacional do 
Porto, mas sobretudo lançou o projecto da Casa da Música. Este projecto contemplou a concepção e construção de um equipamento especificamente destinado à actividade musical e o desenvolvimento de um projecto artístico multifacetado (no qual se incluem o já conhecido e activo Remix Ensemble, o Estúdio de Ópera ou o Departamento Educativo). No domínio da programação, promoveu e acolheu um grande número de iniciativas em diversas áreas musicais (a erudita, o jazz, o pop/rock, a música electrónica e de dança, a música popular...). ${ }^{15}$ O efeito produzido pela realização da Porto 2001 é, aliás, visível no gráfico 6, quando comparamos o número de registos de espectáculos agenda realizados no Grande Porto em 2000 e 2001.

Ainda assim, nesta área urbana, os festivais parecem desempenhar um importante papel de dinamização do espectáculo musical, provavelmente mais importante nos concelhos mais periféricos (e podemos lembrar a título de exemplo o Matosinhos Jazz, o Festival Internacional de Música da Póvoa do Varzim, o Festival Internacional de Música de Espinho, o Festival de Música da Maia).

O terceiro aspecto que vale a pena realçar do padrão de distribuição geográfica dos modelos de produção de espectáculo diz respeito ao facto de, fora dos grandes centros urbanos (Lisboa e Porto), o número de espectáculos realizados no âmbito de festivais superar aqueles que resultam da actividade e iniciativa locais (espectáculos agenda). Tal facto parece significar que a vida musical da maioria das cidades portuguesas depende quase em absoluto da realização de festivais de música (sejam eles de que tipo forem).

Mais uma vez, a adopção de uma estratégia de aproximação focalizada sobre a oferta de concertos fora dos dois grandes centros urbanos contribui para a identificação de variações específicas. Estas ajudam a introduzir nuances na tendência que acabámos de enunciar e permitem anotar diferenças que remetem para traços concretos de ambientes culturais locais. Os gráficos 7 e 8 apresentam a variação geográfica do tipo de espectáculos no país a uma escala mais aproximada da realidade (tendo sido retiradas as ocorrências na Grande Lisboa e no Grande Porto).

As principais nuances introduzidas pela perspectiva dada por estes dois gráficos dizem respeito aos maiores ou menores equilíbrios entre os três modos de promoção do espectáculo que podemos observar em diferentes regiões.

De um modo geral, podemos observar que as regiões do Norte do país e do Litoral (Centro e Sul) reflectem uma oferta de espectáculos mais dinâmica

\footnotetext{
${ }^{15}$ Sobre o peso da componente musical no programa de intervenção da Capital Europeia da Cultura, ver Fortuna et al., 2003, capítulo 3.
} 
do que as regiões do Interior. Um dado já esperado, considerando a maior densidade da sua rede urbana e da população aí residente. Não obstante, as regiões do Norte merecem uma atenção particular por ser nestas que se observa um maior equilíbrio entre os vários contextos de produção de espectáculos.

\section{GRÁFICO 7 - Distribuição geográfica dos registos de Festas, Festivais e Espectáculos agenda} por NUTS II e III (excluindo o Grande Porto e a Grande Lisboa), no ano de 2000

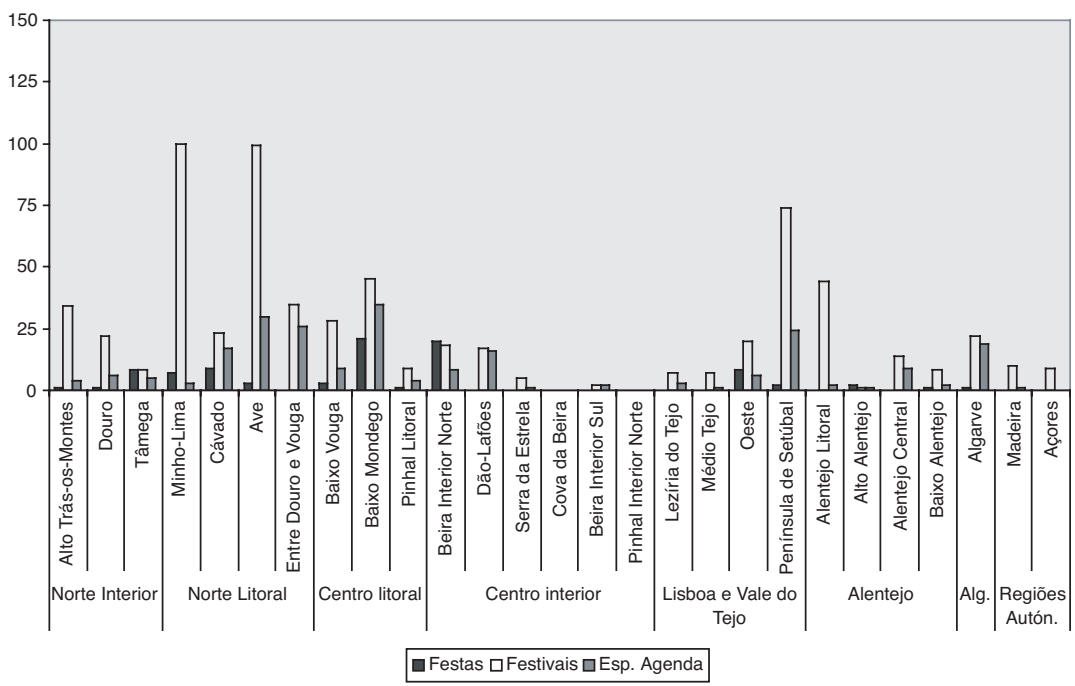

GRÁFICO 8 - Distribuição geográfica dos registos de Festas, Festivais e Espectáculos agenda por NUTS II e III (excluindo o Grande Porto e a Grande Lisboa), no ano de 2001

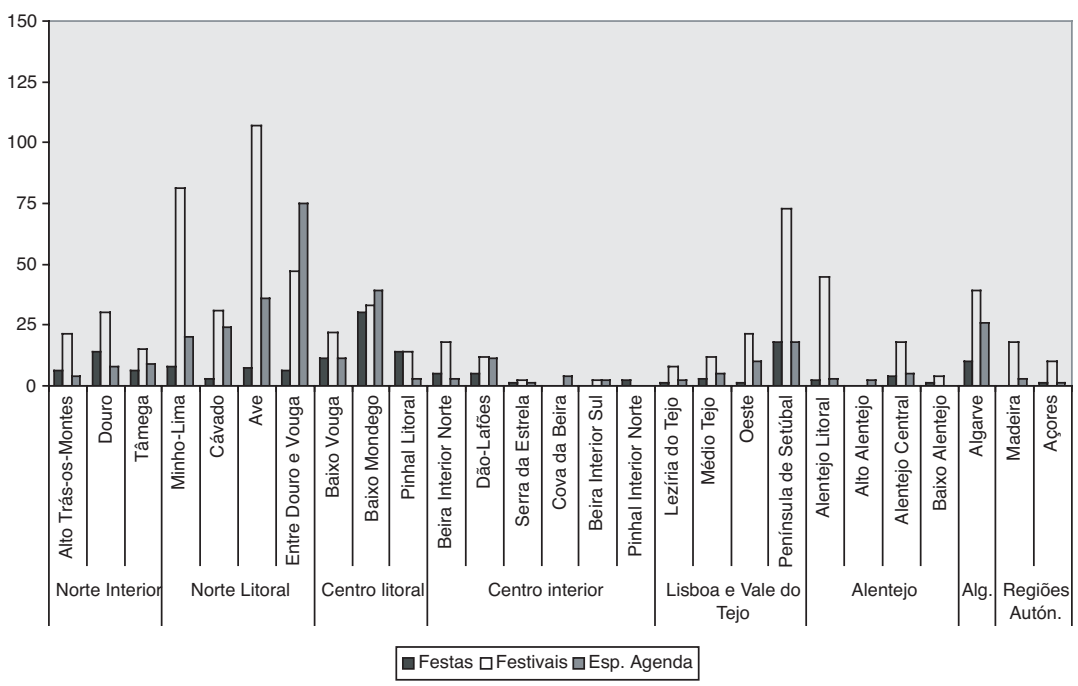


Nas regiões do interior (sobretudo do Centro Interior e das franjas mais interiores da região de Lisboa e Vale do Tejo), o panorama surge absolutamente distinto. A oferta de espectáculos apresenta-se de tal forma reduzida que não tem qualquer significado a distinção entre os seus modos de produção. Estes dados parecem indiciar a manifestação de uma assimetria de tal maneira forte que, sobretudo se pensarmos na comparação com a Grande Lisboa e o Grande Porto, poderemos entender a situação destas regiões como estando próxima do "grau zero" do mercado do espectáculo musical. Claro que deveremos considerar que o trabalho sobre dados de imprensa amplifica exponencialmente a assimetria entre estas duas realidades, porque a distância física entre as duas contribui para tornar invisíveis os acontecimentos mais longínquos.

Nas regiões do litoral, os dados permitem identificar três situações com traços relativamente distintos. A primeira refere-se às regiões da periferia do Grande Porto, nomeadamente, as regiões do Cávado, Ave e de Entre Douro e Vouga. Embora caracterizadas por desequilíbrios entre os diferentes circuitos do espectáculo, estas regiões apresentam volumes de oferta que se distanciam de outras zonas do litoral e dão continuidade à dinâmica observada no Grande Porto. A segunda situação diz respeito a duas regiões onde o equilíbrio entre os três circuitos do espectáculo parece ser o maior, revelando-se como um indicador positivo. Trata-se dos casos da região do Baixo Mondego (na qual se situa a cidade de Coimbra) e do Algarve (Faro e outras cidades algarvias), onde os registos de espectáculos agenda se aproximam mais dos registos de festivais. Coimbra (ou o Baixo Mondego) apresenta, aliás, a peculiaridade de uma representação aproximada dos registos de espectáculos agenda, de festivais e de festas, dando conta de uma arena de espectáculos musicais senão muito rica, pelo menos mais equilibrada do que a da maioria das cidades médias portuguesas. ${ }^{16}$

Por último, a terceira situação que vale a pena assinalar refere-se a regiões que, ao contrário das duas anteriores, projectam a sua imagem na arena do espectáculo musical português com base na oferta promovida pela realização de festivais com forte projecção nacional. São disso exemplo as regiões do Minho-Lima, do Alentejo Litoral ou mesmo da Península de Setúbal e os festivais de Vilar de Mouros e de Paredes de Coura (na região de Minho-Lima), do Seixal e do Meco (na Península de Setúbal) ou ainda do festival do Sudoeste Alentejano (na Zambujeira do Mar, Alentejo Litoral).

\footnotetext{
${ }^{16}$ Estes dados vão no mesmo sentido do que foi observado no estudo cujos resultados se encontram publicados em Santos et al. (1999), Fortuna e Abreu (2001), Abreu (2001), Silva et al. (2002). Nesse trabalho tivemos oportunidade de observar que, por comparação com outras cidades do litoral Centro e Norte do país, Coimbra apresentava não apenas elevados índices de consumos e práticas culturais, como também indicadores de uma oferta cultural variada e importante.
} 
Esta tendência, observada a partir da imagem projectada na imprensa nacional, confirma a tese da macrocefalia da esfera cultural portuguesa e, mais particularmente, do seu campo musical. Este parece ter a sua base geográfica nas cidades de Lisboa e Porto (ainda que com grande vantagem para Lisboa), projectando-se para todo o país através da realização de uma conjunto diverso de eventos, de realização mais ou menos regular, mas com uma inscrição temporal no ano muito curta.

Em síntese, as três grandes tendências que acabámos de apresentar dão conta de outras tantas dimensões em que é possível operacionalizar e comprovar a volátil estrutura do mercado da música ao vivo no nosso país. E embora o estatuto da informação empírica nos obrigue a uma dose substancial de prudência na interpretação dos resultados, parece-me que os dados são indicativos de uma situação que, para além de reconfirmar a macrocefalia cultural do país, revela também uma aparente fragilidade nos modelos de estruturação da oferta cultural. Esta parece revelar-se fortemente dependente de plataformas de intermediação e distribuição cultural pouco convencionais, com um reduzido grau de institucionalização e uma articulação pouco clara com os ambientes culturais locais.

\section{Considerações e interrogações finais}

Esta perspectiva exige, contudo, a complexificação do discurso analítico, levando-nos a questionar o significado do recurso relativamente constante ao formato dos "festivais" na organização e produção do espectáculo musical. Não só porque esse é um recurso disponível para os agentes culturais e políticos em contextos com ambientes culturais mais depauperados, mas, sobretudo, porque eles se mostram igualmente recorrentes nos dois maiores e mais ricos centros culturais do país.

Neste sentido, vale a pena considerar algumas das características gerais dos festivais de música. Estes acontecimentos concentram num curto período de tempo e num contexto espacial delimitado uma programação intensa de concertos, frequentemente associada a programas complementares de conferências, seminários, oficinas de trabalho, etc., normalmente orientados para um género musical ou uma temática particular. Este formato geral é caracterizado por alguns traços essenciais - flexibilidade, intensidade e impacto -, que merecem a nossa atenção pelas implicações que acarretam relativamente aos modelos de acção cultural que veiculam.

A flexibilidade decorre do modelo funcional assumido por este tipo de eventos - a organização por projecto. Como referem Sydow e Staber (2002), sendo caracterizados por uma duração temporal limitada e por uma localização espacial circunscrita, a produção destes eventos proporciona o recurso 
a estruturas funcionais pequenas e ligeiras, com um número reduzido e flexível de pessoas, envolvendo recursos materiais e financeiros relativamente reduzidos (sobretudo se comparados com os recursos necessários ao funcionamentos de instituições ou empresas permanentes).

A intensidade, como assinalam Dowd, Liddle e Nelson (2004), refere-se à densidade de actividades (performativas, mas também comunicativas, de ensaio, aprendizagem ou de audição) desenvolvidas no tempo e no espaço do evento. Essa intensidade parece criar condições particulares de envolvimento para criadores e intérpretes, intermediários da difusão e da crítica, bem como para espectadores, compensando a pouca frequência de realização destes eventos.

O impacto resulta dos efeitos produzidos por estes eventos no interior das esferas ou cenas musicais e no seu exterior (Dowd, Liddle e Nelson, 2004). Para as cenas envolvidas, os efeitos podem ser múltiplos: reforço das actividades criativas e performativas dos intervenientes num determinado campo musical (como, por exemplo, o jazz); estímulo à criação inovadora; divulgação de novas correntes e intérpretes; consagração de géneros, autores ou intérpretes; formação, consolidação e alargamento de públicos; estímulo ao consumo... Mas estes efeitos não se restringem ao espaço interno dos universos musicais. Transbordam e contagiam os espaços e as comunidades onde têm lugar estes eventos. Constituem, por isso, instrumentos de acção e política cultural de instituições públicas como de instituições privadas. Intervêm em espaços urbanos concretos e projectam imagens positivas desses espaços e das suas comunidades, servindo estratégias de política e marketing urbanos.

Trata-se de três características que não serão indiferentes a tendências reconhecidas nas esferas culturais e nos domínios da acção política. A primeira dessas tendências é a popularização de modelos de organização por projecto nos domínios da produção cultural que, como refere Pierre-Michel Menger (2002), se coadunam não apenas com o modelo individualizado da produção de carreiras artísticas e com a autonomia dos seus desempenhos, mas também com a escassez de recursos materiais e financeiros disponíveis para a produção cultural. A segunda tendência diz respeito à intensa mercantilização das diferentes esferas musicais, visível na acção de intermediários da produção, distribuição e promoção (frequentemente de perfil empresarial), mas também nas estratégias de criadores e intérpretes, que adaptam os formatos de criação e produção dos espectáculos a lógicas de mercado e investem na gestão mercantil das suas actividades. Atitudes que, como mostra Pierre François (2004), são observáveis mesmo em nichos de actividade relativamente especializados. Por último, a tendência 
para a multiplicação das exigências de legitimação da acção cultural, sentidas e partilhadas por agentes culturais e políticos, que se reflectem em diversas estratégias de maximização dos efeitos externos das iniciativas culturais.

Neste contexto, os festivais surgem como um formato destinado ao sucesso, respondendo não apenas a dinâmicas e interesses internos às próprias comunidades artísticas, mas também a constrangimentos e procuras externas. No entanto, tendo em atenção as especificidades do contexto cultural português, vale a pena colocar algumas questões. De facto, em que medida é que o recurso mais ou menos sistemático a formatos de festival na produção de espectáculos de música pode permitir superar os conhecidos défices de estruturação, institucionalização, produção, participação e consumo que caracterizam os ambientes culturais das nossas cidades? A inserção desses festivais em circuitos de produção de espectáculos organizados a escalas nacionais e, sobretudo, internacionais permitirá em alguma circunstância gerar efeitos de dinamização dos mercados culturais locais, sabendo-se que estes são particularmente rarefeitos e débeis, mesmo nos segmentos mais massificados das indústrias culturais? Permitirão os festivais inserir os criadores e intérpretes locais em circuitos e redes de actividade mais amplas, funcionando como instrumentos de institucionalização dessas redes? Contribuirão os festivais para a captação e ampliação de públicos ou mesmo de audiências de música? E que públicos? Locais, nacionais, internacionais?

O número de interrogações poderia mesmo ser multiplicado sem que tal significasse um simples exercício de retórica. A formulação de tais perplexidades decorre do contraste observado entre os contextos urbanos e culturais identificados na literatura acerca das tendências contemporâneas da organização e produção da cultura (Scott, 1999; Menger, 2002) e as características identificadas para as cidades e as esferas culturais do nosso país. De facto, a intensificação do recurso a modalidades de organização e produção cultural por projecto é recorrentemente descrita como uma característica de ambientes culturais particularmente densos e consolidados. Neles se encontram estabelecidas múltiplas redes de actores, instituições e agentes económicos que são mobilizáveis na produção de projectos complexos e inovadores, mas limitados na sua duração espácio-temporal. O carácter efémero dos projectos é, nesse caso, compensado pelo seu enraízamento em redes de interacção que se caracterizam pela capacidade de reprodução e transformação para além de cada projecto.

O trabalho que aqui acabei de apresentar revela-nos, acerca do nosso país e da sua esfera do espectáculo musical, em concreto, uma situação completamente diversa. Neste caso, o recurso à produção de festivais ocorre 
sobretudo em contextos urbanos de baixa densidade cultural. E, do meu ponto de vista, as circunstâncias específicas desta aparente "vanguarda" na acção cultural (e musical, em particular) podem indiciar duas tendências de efeitos recíprocos. Por um lado, a intensificação das relações de dependência dos mercados musicais locais relativamente a circuitos de distribuição fortemente mercantilizados e globalizados e a sua institucionalização como mercados preferenciais da distribuição e do consumo, mais do que como contextos de criação e produção. Por outro lado, a reiterada volatilização de uma oferta cultural marcada pelo peso da acção cultural das instituições públicas locais e, em particular, dos órgãos locais do poder político que optam por estratégias de intervenção cultural pautadas pela procura de efeitos de impacto imediato e por lógicas de minimização de custos e pela desejada maximização de limitados recursos humanos, financeiros e institucionais. Tendências que, a verificarem-se, podem acentuar as fragilidades das esferas da criação e produção musical nacionais.

\section{Referências Bibliográficas}

Bennett, Andy (2004), "Consolidating the Music Scenes Perspective”, Poetics, 32, 223 -234 .

Conde, Idalina (1997), “Cenários de práticas culturais em Portugal (1979-1995)”, Sociologia - Problemas e Práticas, 23, 117-188.

Costa, Pedro (1999), "Efeito de 'meio' e desenvolvimento urbano: o caso da fileira da cultura”, Sociologia - Problemas e Práticas, 29, 127-149.

Costa, Pedro (2000), "Centros e margens: produção e práticas culturais na Área Metropolitana de Lisboa”, Análise Social, XXXIV(153), 957-983.

Costa, Pedro (2002), "The Cultural Activities Cluster in Portugal. Trends and Perspectives”, Sociologia - Problemas e Práticas, 38, 99-114.

Crane, Diane (1992), The Production of Culture. Media and Urban Arts. London: Sage.

Dowd, Timothy J.; Liddle, Kathleen; Nelson, Jenna (2004), “Music Festivals as Scenes: Examples from Serious Music, Womyn's Music, and SkatePunk", in Andy Bennett; Richard A. Peterson (orgs.), Music Scenes: Local, Translocal and Virtual. Nashville: Vanderbilt UP.

Ferreira, Claudino (1998), “A Exposição Mundial de Lisboa de 1998”, Revista Crítica de Ciências Sociais, 51, 43-67.

Fortuna, Carlos et al. (2003), Intermediários culturais, espaço público e cultura urbana. Um estudo sobre a influência dos circuitos culturais globais em algumas cidades portuguesas. Relatório de investigação do projecto POCTI/SOC/13151/1998. Coimbra: Centro de Estudos Sociais. 
Fortuna, Carlos (2002), "Culturas urbanas e espaços públicos: sobre as cidades e a emergência de um novo paradigma sociológico", Revista Crítica de Ciências Sociais, 63, 123-148.

Fortuna, Carlos; Silva, Augusto Santos (2001), "A cidade do lado da cultura: espacialidades sociais e modalidades de intermediação cultural”, in Boaventura Sousa Santos (org.), Globalização: Fatalidade ou utopia. Porto, Afrontamento, 409-461.

Fortuna, Carlos; Ferreira, Claudino; Abreu, Paula (1999), "Espaço público urbano e cultura em Portugal”, Revista Crítica de Ciências Sociais, 52/53, 85-117.

François, Pierre (2004), "Prototype, concurrence et marché: le marché des concerts de musique ancienne”, Revue Française de Sociologie, 45(3), 529-559.

Lash, Scott; Urry, John (1994), Economies of Signs and Space. London: Sage.

Martinho, Teresa; Neves, José Soares (1999), "Festivais de música em Portugal”, Folha OBS, 1, 1-5.

Maisonneuve, Sophie (2002), Le disque et la musique classique en Europe, 1877-1949. Florence : European University Institute.

Menger, Pierre-Michel (1993), "L'hégémonie parisienne. Économie et politique de la gravitation artistique”, Annales. Économies, Sociétés, Civilisations, 48(6), 1565-1600.

Menger, Pierre-Michel (2002), Portrait de l'artiste en travailleur. Métamorphose du capitalisme. Paris: Éditions du Seuil e La République des Idées.

Neves, José Soares (2000), Despesas dos municípios com cultura. Lisboa: Observatório das Actividades Culturais.

Santos, Maria de Lourdes Lima dos (org.) (1998), As políticas culturais em Portugalrelatório nacional. Programa europeu de avaliação das políticas culturais nacionais. Lisboa: Observatório das Actividades Culturais.

Scott, Allen J. (1999), “The Cultural Economy: Geography and the Creative Field”, Media, Culture E Society, 21(6), 807-817.

Silva, Augusto Santos (2002), "A dinâmica cultural das cidades médias: uma sondagem do lado da oferta", in Carlos Fortuna; Augusto Santos Silva (orgs.), Projecto e circunstância. Culturas urbanas em Portugal. Porto: Afrontamento, 65-107.

Silva, Augusto Santos (1994), Tempos cruzados: Um estudo interpretativo da cultura popular. Porto: Afrontamento.

Silva, Augusto Santos et al. (1998), "Agentes culturais e públicos para a cultura: alguns casos de uma difícil relação", Cadernos de Ciências Sociais, 18, 67-105.

Sydow, Jörg; Staber, Udo (2002), “The Institutional Embeddedness of Project Networks: The Case of Content Production in German Television”, Regional Studies, 36(3), 215-227. 